\title{
The case for causal influences of action videogame play upon vision and attention
}

\author{
Árni Kristjánsson
}

Published online: 6 February 2013

(C) Psychonomic Society, Inc. 2013

\begin{abstract}
Over the past decade, exciting findings have surfaced suggesting that routine action videogame play improves attentional and perceptual skills. Apparently, performance during multiple-object tracking, useful-field-ofview tests, and task switching improves, contrast sensitivity and spatial-resolution thresholds decrease, and the attentional blink and backward masking are lessened by short-term training on action videogames. These are remarkable findings showing promise for the training of attention and the treatment of disorders of attentional function. While the findings are interesting, evidence of causal influences of videogame play is not as strong as is often claimed. In many studies, observers with game play experience and those without are tested. Such studies do not address causality, since preexisting differences are not controlled for. Other studies investigate the training of videogame play, with some evidence of training benefits. Methodological shortcomings and potential confounds limit their impact, however, and they have not always been replicated. No longitudinal studies on videogame training exist, but these may be required to provide conclusive answers about any benefits of videogame training and any interaction with preexisting differences. Suggestions for methodological improvement are made here, including recommendations for longitudinal studies. Such studies may become crucial for the field of attentional training to reach its full potential.
\end{abstract}

Keywords Attention · Perceptual learning · Videogames · Visual attention

\footnotetext{
Á. Kristjánsson $(\triangle)$

Department of Psychology, School of Health Sciences,

University of Iceland, Gimli v. Sturlugötu,

101 Reykjavik, Iceland

e-mail: ak@hi.is
}

The question of whether perceptual and attentional skills can be trained is of major scientific, practical, and clinical value. Disorders of attention such as attention-deficit or attentiondeficit hyperactivity disorder can severely affect normal functioning (Barkley, 2006), as can attentional disorders due to neurological damage, such as hemispatial neglect (Heilman, Watson, \& Valenstein, 2003; Saevarsson, Halsband, \& Kristjánsson, 2011) or Balints syndrome (Rafal, 2001). Abnormal attentional biases have been found to play a role in anxiety disorders (see, e.g., Bar-Haim, 2010, for a review), and effects such as inattentional blindness (Most, Scholl, Clifford, \& Simons, 2005; Simons, 2000), change blindness (Rensink, O’Regan, \& Clark, 1997; Simons \& Rensink, 2005), and the attentional blink (Kristjánsson \& Nakayama, 2002; Raymond, Shapiro, \& Arnell, 1992) highlight the important role that attention plays in normal vision.

If attentional abilities can be improved, or modified, through training, this rightly generates tremendous interest. A large scientific literature suggests that training on action videogames improves visual and attentional function (see, e.g., Bavelier, Green, Pouget, \& Schrater, 2012; Spence \& Feng, 2010, for recent reviews). Furthermore, training effects from videogames appear to transfer better between tasks than do most other types of learning (Boot, Blakely, \& Simons, 2011; Green \& Bavelier, 2012). I will argue, however, that before strong conclusions can be drawn about causal effects of videogame play upon vision and attention, a number of key questions need to be answered, and methodological improvement is needed. The most pressing issues are the following (elaborated upon below):

1. Claims for a causal role of videogames in improving attentional function need much stronger support.

2. Possible preexisting differences between habitual videogame players and nonplayers constitute a serious confound in many studies. This preselection alternative has not been ruled out. 
3. Differences between habitual videogame players and nonplayers are not always observed, and training effects from videogames have not consistently been found.

4. Chicken-and-egg questions of training versus preexisting differences have often been successfully addressed with longitudinal research, which is the next logical step for the field.

\section{The issue of causality}

Researchers indeed have good reason to believe that habitual videogame players (VGPs) perform better than those who do not play (NVGPs) on tests of visuospatial attention and perception. But the causality behind this difference is far less certain. Typically, participants with experience of videogame play are recruited and compared to groups with little videogame experience. Participants from these two populations have often been found to differ in performance on various tasks involving visuospatial attention and visual function (Cain, Landau, \& Shimamura, 2012; Castel, Pratt, \& Drummond, 2005; Chisholm, Hickey, Theeuwes, \& Kingstone, 2010; Colzato, van Leeuwen, van den Wildenberg, \& Hommel, 2010; Green \& Bavelier, 2003, 2006a, 2006b, 2007; Hubert-Wallander, Green, Sugarman, \& Bavelier, 2011; Karle, Watter, \& Shedden, 2010; Li, Polat, Makous, \& Bavelier, 2009; Li, Polat, Scalzo, \& Bavelier, 2010; Sungur \& Boduroglu, 2012; West, Stevens, Pun, \& Pratt, 2008), and functional neural activity has been found to differ between the groups (Bavelier, Achtman, Mani, \& Föcker, 2012; Granek, Gorbet, \& Sergio, 2010; Mishra, Zinni, Bavelier, \& Hillyard, 2011; Wu et al., 2012).

Why do these difference occur? One possible causal chain of events is that some people are good at playing videogames that require certain attentional abilities, and thus play more videogames. They end up in the VGP group, and perform better than NVGPs on the tests. But many studies refer to training studies such as Green and Bavelier (2003) to support claims of causal influences of habitual action videogame play on vision and attention. Green and Bavelier (2003) trained two groups of NVGPs for $10 \mathrm{~h}$ on an action videogame and on a placebo task. They found attentional training effects from the action videogame, and concluded with the very influential claim that " 10 days of training on action video-games is sufficient to increase the capacity of visual attention, its spatial distribution and its temporal resolution" (p. 536). Other studies have since reported similar training effects for a variety of tasks (Feng, Spence, \& Pratt, 2007; Green \& Bavelier, 2006a, 2006b, 2007; Li et al., 2009; Li et al., 2010; but see Boot, Kramer, Simons, Fabiani, \& Gratton, 2008, for a notable exception, further discussed below).
But such training studies do not rule out the preselection alternative for studies in which participants are selected on the basis of self-reported history of videogame play. For a causal claim, control over the independent variables is needed, but when differences are found between VGPs and NVGPs, this basic principle is violated when experience of videogame play is assumed to cause any differences. It cannot be assumed that, even though a short-term training effect is found for a subsample of observers with little videogame experience, preexisting differences do not apply to other samples from the population.

The critical point is that studies based on recruitment from experience provide no information about any causal influences of videogame play on vision and attention, even if training effects have been found for other populations. For this argument to be valid, initially comparable groups need to be trained. Recruitment of experienced versus inexperienced players is, nevertheless, common practice, and causal language is often used. At the Vision Sciences 2012 conference, nine presentations concerned the effects of videogame play on attentional and visual function. In six of the nine studies, observers were recruited on the basis of preexisting training. Causal language with regard to the effects of videogame play was used in four of those. Note also that studies in which VGPs and NVGPs are trained and their learning rates assessed, such as in studies of so-called "learning to learn" (Bejjanki, Sims, Green, \& Bavelier, 2012; Zhang et al., 2012; see Bavelier et al., 2012b, for the basic argument), involve similar confounds when the participants are selected on the basis of experience.

\section{Lack of practice effects for control groups}

To make a causal link between videogame play and attentional abilities, groups that are in every relevant way comparable should receive differential training, one on the type of videogame of interest, the other on a suitable placebo task. Testing groups with differential training histories on videogames has no bearing on causality. Such studies may, at best, suggest areas in which training may have an effect.

But a puzzling issue exists regarding many of the training studies currently available: The control groups that do not receive action videogame training do not improve on the task of interest. For example, Green and Bavelier (2007) argued that action videogame play altered the spatial accuracy of vision. In their Experiment 2, one group was trained on an action videogame and another on Tetris. The action videogame group improved significantly following training (indicating diminished crowding), while the Tetris group did not. The interpretation was that videogame play improves the spatial accuracy of vision. But the finding can be rephrased as follows: Not playing action videogames 
prevents observers from learning a task. This is logically an equally valid inference. Similar nonimprovement of control groups has been seen in other videogame training studies, of improvements in contrast sensitivity (Li et al., 2009) and decreases in susceptibility to backward masking (Li et al., 2010). Feng et al. (2007) found a similar nonbenefit for a group that did not play action videogames from repeated testing on a mental-rotation task and for the useful-field-ofview task (see also Green \& Bavelier, 2003, 2006a, 2006b; and see Strobach, Frensch, \& Schubert, 2012, and Wu et al., 2012, for recent examples).

One of the best-known examples of attentional training in the literature is contextual cueing (Chun \& Jiang, 1998; see, e.g., Chun, 2000, and Kristjánsson, 2006, for reviews), in which observers are trained on "old" versus "new" search displays. The main finding is that search times become slightly but notably faster for the old displays. But importantly, the largest effects are the overall training effects for both old and new displays. Visual and attentional performance usually improves with practice (Chun \& Nakayama, 2000; Gibson, 1969; Karni \& Sagi, 1993; Kristjánsson \& Nakayama, 2003; Seitz \& Watanabe, 2005), but the videogame training literature suggests that action videogames may be needed for improvement (see Ackerman, Kanfer, \& Calderwood, 2010, for related discussion). Interestingly, Boot et al. (2008) did not observe differential videogame training effects on a large number of tasks, in contrast with other videogame training studies. Both the trained und untrained groups improved between tasks, and the lack of a training difference between the groups was therefore due to similar improvement.

\section{Issues of replication}

When provocative findings are reported, this requires replication across different laboratories. Boot et al. (2008) found no differential training effects for 82 college students from $20+$ hours of training on a first-person action videogame, a strategy game, Tetris, or no training for baseline. Very little, if any, additional benefits were found on a wide range of tasks involving vision, attention, executive control, and memory from action videogame play as compared with the other tasks. So, even though the results from videogame training studies are certainly suggestive, probably the most comprehensive training study to date found no superior benefits of action videogame training.

A difference between VGPs and NVGPs has not always been seen (Boot et al., 2008; Irons, Remington, \& McLean, 2011; Murphy \& Spencer, 2009). Donohoe, James, Eslick, and Mitroff (2012) found that VGPs and NVGPs alike performed poorly on visually demanding tasks while simultaneously answering demanding questions through a speakerphone. Irons et al. (2011) found no difference between VGPs and NVGPs on a flanker task, in contrast with previous findings. In a large cross-sectional study of 333 children, Ferguson, Garza, Jerabeck, Ramos, and Galindo (2013) found no effect of exposure to videogames on visuospatial cognition. Note that the only studies in which participants have been recruited on the basis of experience that may carry any information about causality are the studies that have not found an experience-dependent difference, since there is no difference for preselection to explain.

\section{Other issues}

Boot, Blakely, and Simons (2011) pointed out a number of serious pitfalls that "no published gaming study has successfully avoided" (p. 1). They discussed how overt recruiting may influence performance through demand characteristics. Beyko, Stothart, and Boot (2012) reported preliminary findings on 30 observers showing that a majority of action videogame players guessed that they had been recruited to participate in a study investigating the superior skills of videogame players, while a minority of nongamers guessed this. While these early findings must be interpreted with caution, the implications regarding differences in motivational levels are obvious. Boot et al. (2011) also argued that training studies often suffer from a lack of proper placebo control. This is a particularly thorny issue, especially if observers are likely to try and guess what the study is about. Covert recruiting with postexperiment questionnaires (see, e.g., Donohue, Woldorff, \& Mitroff, 2010) improves upon this situation but is rarely used.

Nonaction videogames like Tetris or Sims are often used for comparison with action videogames. Beyko et al. (2012) reported that participants rated Tetris as being less likely to improve performance on the useful-field-of-view task than the action videogame Unreal. While preliminary, the findings put in question whether the control tasks fulfill their intended placebo role. Boot et al. (2011) discussed what occurs during videogame training. Any training effects (or group differences) may reflect strategy changes (see, e.g., Clark, Fleck, \& Mitroff, 2011) rather than perceptual or attentional effects. In fact, the potential mechanisms behind attentional training from videogames are unclear.

If videogame play alters attentional performance, in some cases (the evidence is not unequivocal), we lack insight into the boundary conditions of such learning and possible mechanisms. Why do Tetris or MarioBros not work? Will MarioKart cause improved attention and vision, since the participant is in the driver seat, while MarioBros will not, since it involves an "external" view? Will this work on the small screen of a Nintendo DS, or is a large monitor needed? What are the key aspects of action videogames that cause 
attentional improvement? Action-videogame play per se is presumably not the critical ingredient. The interesting scientific question will be when and how attention can be trained and what the mechanisms are.

Another issue, usually dealt with as being trivial, is that expert VGP males outnumber expert females to such a degree that many studies exclusively recruit males, since there are not enough females for gender-balanced groups. But if we accept that videogame training causes the differences, what is the reason for the gender imbalance? Alarm bells should ring here. Could preexisting differences in attentional ability between males and females explain this? Here, longitudinal research could provide answers (see below). Interestingly, recent evidence has suggested that personality may influence game-playing preferences (Quick, Atkinson, \& Lin, 2012; Ventura, Shute, \& Zhao, 2013), and Hoeft, Watson, Kesler, Bettinger, and Reiss (2008) reported greater mesocorticolimbic activation in male than in female college students during videogame play, which could be related to reward and motivational levels. Feng et al. (2007) observed that gender differences in the distribution of spatial attention were diminished with 10-h training on action videogames. All of these findings raise exciting questions regarding interactions of preexisting differences and training. Such questions would ideally be addressed with longitudinal research.

The findings in this literature are headline-grabbing, so the questions being asked about it are not trivial. The societal implications must be considered, since the published research will influence behavior. There may be benefits to not playing videogames (see, e.g., Anderson \& Bushman, 2001; Cummings \& Vandewater, 2007): For instance, beneficial physical activities are not performed while children play videogames, and attentional demands accompany physical activity. The multiple-object-tracking tasks of basketball, soccer, and team handball, in which opponents need to be avoided and teammates found, may train attentional abilities (see the discussion in Chaddock, Voss, \& Kramer, 2012). How do these benefits compare with those of videogame play?

\section{What next?}

Very interesting differences between experts and novices are often observed, and this clearly requires explanation. But more information is needed for satisfactory answers to questions about causality. The training approach is needed for any claims that first-person action videogame experience causes any alternation of attentional function. A drawback is that these studies reflect short-term learning (typically over a few days), and another is that the training studies by necessity only test NVGPs, carrying the unfortunate implicit assumption that VGPs and NVGPs are initially comparable.
All of this highlights the need for longitudinal research. Ten years on from the publication of Green and Bavelier's (2003) influential study, there is still no evidence from a longitudinal study. Longitudinal studies have been critical to the understanding of some of the most pressing issues within psychology (Bouchard, Lykken, McGue, Segal, \& Tellegen, 1990; Chess \& Thomas, 1990; Nilsson et al., 2004; Rietveld, Hudziak, Bartels, van Beijsterveldt, \& Boomsma, 2004; Shaw et al., 2006). They are especially useful for disentangling the effects of different variables that are possibly correlated, and they have high external validity. Note that cross-sectional studies such as those of Dye, Green, and Bavelier (2009) and Dye and Bavelier (2010) demonstrating attentional differences between VGPs and NVGPs for various age groups will not replace longitudinal studies, since preexisting differences were not controlled for. In fact, their findings of attentional differences between VGPs and NVGPs in the 7- to 10-year-old age group could be evidence for preexisting differences between VGPs and NVGPs. Even though the differences are larger for older groups, a preexisting difference may be exacerbated with practice.

As of now, no longitudinal study of videogame play and the development of visual and attentional function is available in the literature. However, a longitudinal study in which a large group of children is tested regularly as their behavior (including videogame play) is monitored is timely. Obtaining repeated measures of visuospatial abilities at various ages while activity is measured would allow for an assessment of independent effects from preexisting differences, videogame use, and other variables of interest. Profoundly interesting questions about the training of attention, individual differences in attentional function and ability, and their interaction might be answered.

\section{Conclusions}

If action videogame training modulates attentional abilities, it rightly grabs the headlines. But this makes it all the more important to tread with caution when inferences are drawn from the available data. The key issues can be summarized as follows:

1. A lot of studies have shown superior performance of VGPs on various tasks, as compared with NVGPs, but even if the number of these studies were infinite with infinitely low $p$ values of group differences, this would not be evidence of causality.

2. Any study in which groups are recruited on the basis of self-reported experience cannot be taken as evidence of training effects. Differential training regimens between two groups that are initially comparable obviously 
improve upon the situation, but this paradigm still involves problems.

3. Longitudinal studies may be the only way of settling the question of training from habitual first-person action videogame play and its interactions with preexisting differences.

The field may be scratching the surface of very interesting questions of interactions of training and innate attentional ability. The key question involves the chicken and the egg, and the next logical step will be to address differences in attentional performance between experts and novices in a longitudinal study in which the contributions of the key variables are assessed.

Author note Support was provided by the research fund of the University of Iceland. I thank Walter Boot, Steinunn Gestsdóttir, Steve Mitroff, Jay Pratt, Daniel J. Simons, Jeremy Wolfe, and an anonymous reviewer for invaluable comments on previous versions of this article.

\section{References}

Ackerman, P. L., Kanfer, R., \& Calderwood, C. (2010). Use it or lose it? Wii brain exercise practice and reading for domain knowledge. Psychology and Aging, 25, 753-766.

Anderson, C. A., \& Bushman, B. J. (2001). Effects of violent video games on aggressive behavior, aggressive cognition, aggressive affect, physiological arousal, and prosocial behavior: A metaanalytic review of the scientific literature. Psychological Science, $12,353-359$.

Bar-Haim, Y. (2010). Attention bias modification (ABM): A novel treatment for anxiety disorder. Journal of Child Psychology and Psychiatry, 51, 859-870.

Barkley, R. A. (2006). Attention-deficit hyperactivity disorder: A handbook for diagnosis and treatment (3rd ed.). New York, NY: Guilford Press.

Bavelier, D., Achtman, R. L., Mani, M., \& Föcker, J. (2012a). Neural bases of selective attention in action video game players. Vision Research, 61, 132-143. doi:10.1016/j.visres.2011.08.007

Bavelier, D., Green, C. S., Pouget, A., \& Schrater, P. (2012b). Brain plasticity through the life span: Learning to learn and action video games. Annual Review of Neuroscience, 35, 391-416. doi:10.1146/ annurev-neuro-060909-152832

Bejjanki, V. R., Sims, C. R., Green, C. S., \& Bavelier, D. (2012). Evidence for action video game induced "learning to learn" in a perceptual decision-making task [Abstract]. Journal of Vision, 12 (9), 287. doi: $10.1167 / 12.9 .287$

Beyko, A., Stothart, C., \& Boot, W. (2012). Exploring the effects of video game experience and motivation on visual processing [Abstract]. Journal of Vision, 12(9), 7. doi:10.1167/12.9.7

Boot, W. R., Blakely, D. P., \& Simons, D. J. (2011). Do action video games improve perception and cognition? Frontiers in Psychology, 2, 226.

Boot, W. R., Kramer, A. F., Simons, D. J., Fabiani, M., \& Gratton, G. (2008). The effects of video game playing on attention, memory, and executive control. Acta Psychologica, 129, 387-398. doi:10.1016/j.actpsy.2008.09.005

Bouchard, T. J., Jr., Lykken, D. T., McGue, M., Segal, N. L., \& Tellegen, A. (1990). Sources of human psychological differences:
The Minnesota Study of Twins Reared Apart. Science, 250, 223 228.

Cain, M. S., Landau, A. N., \& Shimamura, A. P. (2012). Action video game experience reduces the cost of switching tasks. Attention, Perception, \& Psychophysics, 74, 641-647. doi:10.3758/s13414012-0284-1

Castel, A. D., Pratt, J., \& Drummond, E. (2005). The effects of action video game experience on the time course of inhibition of return and the efficiency of visual search. Acta Psychologica, 119, 217230. doi:10.1016/j.actpsy.2005.02.004

Chaddock, L., Voss, M. W., \& Kramer, A. F. (2012). Physical activity and fitness effects on cognition and brain health in children and older adults. Kinesiology Review, 1, 37-45.

Chess, S., \& Thomas, A. (1990). The New York Longitudinal Study (NYLS): The young adult periods. Canadian Journal of Psychiatry, 35, 557-561.

Chisholm, J. D., Hickey, C., Theeuwes, J., \& Kingstone, A. (2010). Reduced attentional capture in action video game players. Attention, Perception, \& Psychophysics, 72, 667-671. doi:10.3758/ APP.72.3.667

Chun, M. M. (2000). Contextual cueing of visual attention. Trends in Cognitive Sciences, 4, 170-178. doi:10.1016/S1364-6613 (00)01476-5

Chun, M. M., \& Jiang, Y. (1998). Contextual cueing: Implicit learning and memory of visual context guides spatial attention. Cognitive Psychology, 36, 28-71. doi:10.1006/cogp.1998.0681

Chun, M. M., \& Nakayama, K. (2000). On the functional role of implicit visual memory for the adaptive deployment of attention across scenes. Visual Cognition, 7, 65-81. doi:10.1080/ 135062800394685

Clark, K., Fleck, M. S., \& Mitroff, S. R. (2011). Enhanced change detection performance reveals improved strategy use in avid action video game players. Acta Psychologica, 136, 67-72. doi:10.1016/j.actpsy.2010.10.003

Colzato, L. S., van Leeuwen, P. J. A., van den Wildenberg, W. P. M., \& Hommel, B. (2010). DOOM'd to switch: Superior cognitive flexibility in players of first person shooter games. Frontiers in Psychology, 1(8), 1-5. doi:10.3389/fpsyg.2010.00008

Cummings, H. M., \& Vandewater, E. A. (2007). Relation of adolescent video game play to time spent in other activities. Archives of Pediatrics \& Adolescent Medicine, 161, 684-689.

Donohue, S. E., James, B., Eslick, A. N., \& Mitroff, S. R. (2012). Cognitive pitfall! Videogame players are not immune to dual-task costs. Attention, Perception, \& Psychophysics, 74, 803-809. doi:10.3758/s13414-012-0323-y

Donohue, S. E., Woldorff, M. G., \& Mitroff, S. R. (2010). Video game players show more precise multisensory temporal processing abilities. Attention, Perception, \& Psychophysics, 72, 1120 1129. doi:10.3758/APP.72.4.1120

Dye, M. W. G., \& Bavelier, D. (2010). Differential development of visual attention skills in school-age children. Vision Research, 50, 452-459. doi:10.1016/j.visres.2009.10.010

Dye, M. W. G., Green, C. S., \& Bavelier, D. (2009). The development of attention skills in action video game players. Neuropsychologia, 47, 1780-1789. doi:10.1016/j.neuropsychologia.2009.02.002

Feng, J., Spence, I., \& Pratt, J. (2007). Playing an action video game reduces gender differences in spatial cognition. Psychological Science, 18, 850-855. doi:10.1111/j.1467-9280.2007.01990.x

Ferguson, C. J., Garza, A., Jerabeck, J., Ramos, R., \& Galindo, M. (2013). Not worth the fuss after all? Cross-sectional and prospective data on violent video game influences on aggression, visuospatial cognition and mathematics ability in a sample of youth. Journal of Youth and Adolescence, 42, 109-122. doi:10.1007/ s10964-012-9803-6

Gibson, E. J. (1969). Principles of perceptual learning and development. East Norwalk, CT: Appleton-Century-Crofts. 
Granek, J. A., Gorbet, D. J., \& Sergio, L. E. (2010). Extensive videogame experience alters cortical networks for complex visuo-motor transformations. Cortex, 46, 1165-1177.

Green, C. S., \& Bavelier, D. (2003). Action video game modifies visual selective attention. Nature, 423, 534-537. doi:10.1038/ nature 01647

Green, C. S., \& Bavelier, D. (2006a). Effect of action video games on the spatial distribution of visuospatial attention. Journal of Experimental Psychology. Human Perception and Performance, 32, 1465-1478. doi:10.1037/0096-1523.32.6.1465

Green, C. S., \& Bavelier, D. (2006b). Enumeration versus multiple object tracking: The case of action video game players. Cognition, 101, 217-245. doi:10.1016/j.cognition.2005.10.004

Green, C. S., \& Bavelier, D. (2007). Action-video-game experience alters the spatial resolution of vision. Psychological Science, 18, 88-94. doi:10.1111/j.1467-9280.2007.01853.x

Green, C. S., \& Bavelier, D. (2012). Learning, attentional control, and action video games. Current Biology, 22, R197-R206.

Heilman, K. M., Watson, R. T., \& Valenstein, E. (2003). Neglect: Clinical and anatomic issues. In T. E. Feinberg \& M. J. Farah (Eds.), Behavioral neurology and neuropsychology (pp. 303-311). New York, NY: McGraw-Hill.

Hoeft, F., Watson, C. L., Kesler, S. R., Bettinger, K. E., \& Reiss, A. L. (2008). Gender differences in the mesocorticolimbic system during computer game-play. Journal of Psychiatric Research, 42, 253-258.

Hubert-Wallander, B., Green, C. S., Sugarman, M., \& Bavelier, D. (2011). Changes in search rate but not in the dynamics of exogenous attention in action videogame players. Attention, Perception, \& Psychophysics, 73, 2399-2412. doi:10.3758/ s13414-011-0194-7

Irons, J. L., Remington, R. W., \& McLean, J. P. (2011). Not so fast: Rethinking the effects of action video games on attentional capacity. Australian Journal of Psychology, 63, 224-231. doi:10.1111/j.1742-9536.2011.00001.x

Karle, J. W., Watter, S., \& Shedden, J. M. (2010). Task switching in video game players: Benefits of selective attention but not resistance to proactive interference. Acta Psychologica, 134, 7078. doi:10.1016/j.actpsy.2009.12.007

Karni, A., \& Sagi, D. (1993). The time course of learning a visual skill. Nature, 365, 250-252. doi:10.1038/365250a0

Kristjánsson, Á. (2006). Rapid learning in attention shifts: A review. Visual Cognition, 13, 324-362. doi:10.1080/13506280544000039

Kristjánsson, Á., \& Nakayama, K. (2002). The attentional blink in space and time. Vision Research, 42, 2039-2050.

Kristjánsson, Á., \& Nakayama, K. (2003). A primitive memory system for the deployment of transient attention. Perception \& Psychophysics, 65, 711-724. doi:10.3758/BF03194808

Li, R., Polat, U., Makous, W., \& Bavelier, D. (2009). Enhancing the contrast sensitivity function through action video game training. Nature Neuroscience, 12, 549-551. doi:10.1038/nn.2296

Li, R., Polat, U., Scalzo, F., \& Bavelier, D. (2010). Reducing backward masking through action game training. Journal of Vision, 10 (14):33, 1-13. doi:10.1167/10.14.33

Mishra, J., Zinni, M., Bavelier, D., \& Hillyard, S. A. (2011). Neural basis of superior performance of video-game players in an attention-demanding task. Journal of Neuroscience, 31, 992-998. doi:10.1523/JNEUROSCI.4834-10.2011

Most, S. B., Scholl, B. J., Clifford, E. R., \& Simons, D. J. (2005). What you see is what you set: Sustained inattentional blindness and the capture of awareness. Psychological Review, 112, 217-242. doi:10.1037/0033-295X.112.1.217
Murphy, K., \& Spencer, A. (2009). Playing video games does not make for better visual attention skills. Journal of Articles in Support of the Null Hypothesis, 6, 1-20.

Nilsson, L.-G., Adolfsson, R., Bäckman, L., de Fries, C. M., Molander, B., \& Nyberg, L. (2004). Betula: A prospective cohort study on memory, health and aging. Aging, Neuropsychology, and Cognition, 11, 134-148.

Quick, J. M., Atkinson, R. K., \& Lin, L. (2012). Empirical taxonomies of gameplay enjoyment: Personality and video game preference. International Journal of Game-Based Learning, 2, 11-31.

Rafal, R. (2001). Balints syndrome. In M. Behrmann (Ed.), Handbook of neuropsychology (2nd ed., pp. 121-141). Amsterdam, The Netherlands: Elsevier.

Raymond, J. E., Shapiro, K. L., \& Arnell, K. M. (1992). Temporary suppression of visual processing in an RSVP task: An attentional blink? Journal of Experimental Psychology. Human Perception and Performance, 18, 849-860. doi:10.1037/0096-1523.18.3.849

Rensink, R. A., O’Regan, J. K., \& Clark, J. J. (1997). To see or not to see: The need for attention to perceive changes in scenes. Psychological Science, 8, 368-373. doi:10.1111/j.1467-9280.1997.tb00427.x

Rietveld, M. J. H., Hudziak, J. J., Bartels, M., van Beijsterveldt, C. E. M., \& Boomsma, D. I. (2004). Heritability of attention problems in children: Longitudinal results from a study of twins, age 3 to 12 . Journal of Child Psychology and Psychiatry, 45, 577-588.

Saevarsson, S., Halsband, U., \& Kristjánsson, Á. (2011). Designing rehabilitation programs for neglect: Could $1+1$ be more than 2 ? Applied Neuropsychology, 18, 95-106.

Seitz, A., \& Watanabe, T. (2005). A unified model for perceptual learning. Trends in Cognitive Sciences, 9, 330-334.

Shaw, P., Lerch, J., Greenstein, D., Sharp, W., Clasen, L., Evans, A.,... Rapoport, J. (2006). Longitudinal mapping of cortical thickness and clinical outcome in children and adolescents with attention-deficit/hyperactivity disorder. Archives of General Psychiatry, 63, 540-549. doi:10.1001/archpsyc.63.5.540

Simons, D. J. (2000). Current approaches to change blindness. Visual Cognition, 7, 1-16.

Simons, D. J., \& Rensink, R. A. (2005). Change blindness: Past, present, and future. Trends in Cognitive Sciences, 9, 16-20. doi:10.1016/j.tics.2004.11.006

Spence, I., \& Feng, J. (2010). Video games and spatial cognition. Review of General Psychology, 14, 92-104.

Strobach, T., Frensch, P. A., \& Schubert, T. (2012). Video game practice optimizes executive control skills in dual-task and task switching situations. Acta Psychologica, 140, 13-24.

Sungur, H., \& Boduroglu, A. (2012). Action video game players form more detailed representation of objects. Acta Psychologica, 139, $327-334$.

Ventura, M., Shute, V., \& Zhao, W. (2013). The relationship between video game use and a performance-based measure of persistence. Computers in Education, 60, 52-58. doi:10.1016/ j.compedu.2012.07.003

West, G. L., Stevens, S. A., Pun, C., \& Pratt, J. (2008). Visuospatial experience modulates attentional capture: Evidence from action video game players. Journal of Vision, 8(16):13, 1-9. doi:10.1167/8.16.13

Wu, S., Cheng, C. K., Feng, J., D’Angelo, L., Alain, C., \& Spence, I. (2012). Playing a first-person shooter video game induces neuroplastic change. Journal of Cognitive Neuroscience, 24, 12861293. doi:10.1162/jocn_a_00192

Zhang, R., Bejjanki, V. R., Lu, Z., Green, S., Pouget, A., \& Bavelier, D. (2012). Action video games playing improves learning to learn in perceptual learning [Abstract]. Journal of Vision, 12(9), 1130. doi:10.1167/12.9.1130 